\title{
New Successive Approximation Methods for Solving Strongly Nonlinear Jaulent-Miodek Equations
}

\author{
Ahmed J.Sabali ${ }^{\text {a,* }}$, Saad A. Manaa ${ }^{\text {a }}$, Fadhil H. Easif ${ }^{\text {a }}$ \\ ${ }^{a}$ Dept. of Mathematic, Faculty of Science, University of Zakho, Zakho, Kurdistan Region, Iraq - (ahmed.sabali, saad.manaa, \\ fadhil.easif)@uoz.edu.krd
}

Received: Sept., 2021 / Accepted: Dec., 2021 / Published: Dec., 2021

https://doi.org/10.25271/sjuoz.2021.9.4.869

\begin{abstract}
:
In this paper, we propose two new techniques for solving system of nonlinear partial differential equations numerically, which we first combine Laplace transformation method into a successive approximation method. Second, we combine Padé $[2,2]$ technique into the first proposed technique. To test the efficiency of our techniques, Jaulent-Miodek system was used, which contains partial differential equations and has strongly nonlinear terms. Experimental results revealed that the first proposed technique gives better results when the interval of $t$ is small in terms of error approximation in tabular and graphical manners. Moreover, the results also demonstrated that the second proposed technique gives better results regardless of the given interval of $t$ in terms of the least square errors.
\end{abstract}

KEYWORDS: Jaulent-Miodek, Successive Approximation Method, Laplace Transformation, Padé Technique

\section{INTRODUCTION}

The majority of scientific problems and occurrences are nonlinear in nature. Except for a few situations, mathematicians, physicists, and engineers are fascinated by nonlinear partial differential equations (NLPDEs). In most cases, accurate solutions to NLPDEs are unavailable. Nonlinear optics, hydrodynamics, plasma physics, radar and rheology, quantum physics, and optical fiber communication, among other domains, use differential equations. There has been a significant amount of research into linear and nonlinear PDE systems. For example, these models appear in the propagation of shallow water waves, ice streaming, the Brusselator model of the chemical reaction-diffusion model, granular matter theory, and several scientific domains such as mathematical biology, solid-state physics, and the fields described above. Because the majority of them lack accurate analytical answers, they must be solved using other approaches (Tracinà \& Khalique, n.d.).

In this paper, the successive approximation method (SAM), and we propose two new techniques for solving strongly nonlinear Jaulent-Miodek (JM) system (Fan, 2003; Veeresha et al., 2019).

The Mathematical model of (JM) equation are:

$$
\begin{gathered}
u_{t}+u_{x x x}+\frac{3}{2} v v_{x x x}+\frac{9}{2} v_{x} v_{x x}-6 u u_{x}-6 u v v_{x} \\
-\frac{3}{2} u_{x} v^{2}=0 \\
v_{t}+v_{x x x}-6 u_{x} v-6 u v_{x}-\frac{15}{2} v_{x} v^{2}=0
\end{gathered}
$$

The exact solitary solution of Eq. (1) as in (Jalili et al., 2008) are:

$$
\begin{aligned}
& u(x, t)=s-\frac{b * k * \operatorname{sech}(k(R t+x))}{2} \\
&-\frac{3 * c *(\operatorname{sech}(k(R t+x)))^{2}}{4}
\end{aligned}
$$

$$
v(x, t)=b+k * \operatorname{sech}(k(R t+x))
$$

Where $s, b, k, R$, and $c$ are arbitrary constants, while $s=\frac{1}{4}\left(c-b^{2}\right), k=\sqrt{c}$, and $R=\frac{1}{2}\left(b^{2}+c\right)$

And initial conditions are:

$$
\begin{aligned}
& u(x, 0)=s-\frac{b * k * \operatorname{sech}(k x)}{2}-\frac{3 * c *(\operatorname{sech}(k x))^{2}}{4} \\
& v(x, 0)=b+k * \operatorname{sech}(k x)
\end{aligned}
$$

\section{BASIC IDEA OF SUCCESSIVE APPROXIMATION METHOD}

SAM is a method used to solve any initial value problem such as $u^{\prime}=f(t, u), \mathrm{u}\left(x, t_{0}\right)=u_{0}$. This method can be expressed mathematically as shown in Eq. (7). For more details about the derivation of this method, the reader is referred to (Manaa et al., 2013). Recently, this method has attracted the attention of many authors such as (Hashem, 2015; Jafari, 2014) due to its simplicity and its outstanding results. Inspired by the aforementioned merits of SAM, we use it in our proposed techniques to be applied to the system of equations (1).

Suppose we have initial value problem:

$$
u^{\prime}=f(t, u), \mathrm{u}\left(x, t_{0}\right)=u_{0}
$$

SAM is used for solving Eq. (4) as follows:

Start with taking the integration for both sides of Eq. (4), to obtain a first approximation $u_{1}(x, t)$

$$
u_{1}(x, t)=u_{0}(x, 0)+\int_{0}^{t} u\left(\eta, u_{0}(x, \tau)\right) d \eta
$$

Then this $u_{1}(x, t)$ is substituted again in the integral of Eq. (5) to obtain a second approximation $u_{2}(x, t)$

$$
u_{2}(x, t)=u_{0}(x, 0)+\int_{0}^{t} u\left(\eta, u_{1}(x, \tau)\right) d \eta
$$

This process can be continued to obtain the $n^{\text {th }}$ approximation or (the general form) of SAM can be written as:

$$
u_{n+1}(x, t)=u_{0}(x, 0)+\int_{0}^{t} u\left(\eta, u_{n}(x, \tau)\right) d \eta
$$

\footnotetext{
* Corresponding author

This is an open access under a CC BY-NC-SA 4.0 license (https://creativecommons.org/licenses/by-nc-sa/4.0/)
} 


\section{LAPLACE TRANSFORMATION}

There are many techniques when we apply Laplace Transformation with any other methods such as, Laplace Substitution Method (Mahavidyalaya, 2012), Laplace Decomposition Method (Mohamed \& Torky, 2013), and the VIM-Laplace-Padé (Abassy et al., 2007), He-Laplace Method (Adam, 2015).

\section{PADE TECHNIQUE}

The main advantage of the Padé approximation over the Taylor series approximation is that the Taylor series approximation can oscillate, resulting in an approximation error bound. Furthermore, in a finite region, Taylor series approximations can never blow up. The Padé approximation is used to address these flaws. A ratio of two polynomials gives the Padé approximation of a function. Using the coefficients in the Tylor series expression of the function, the coefficients of the polynomial in both the numerator and denominator. The Padé approximation of a function, symbolized by $\left[\frac{P_{M}(x)}{Q_{N}(x)}\right]$ or for simplicity $\left[\frac{M}{N}\right]$, is a rational function defined by

$$
\left[\frac{M}{N}\right]=\frac{p_{0}+p_{1} x+p_{2} x^{2}+\cdots+p_{M} x^{M}}{1+q_{1} x+q_{2} x^{2}+\cdots+q_{N} x^{N}}
$$

For further understanding this technique step by step, the reader is referred to (Sabali et al., 2018).

\section{SAM WITH LAPLACE THEN PADE TECHNIQUE}

Here, we use a different technique from that used by (Abassy et al., 2007), which includes the following steps:

Taking Laplace Transformation on both sides of equation (7)

$$
\begin{aligned}
& L\left(u_{n+1}(x, t)\right)=L\left(u_{0}(x, 0)\right. \\
& \left.+\int_{0}^{t} u\left(\eta, u_{n}(\eta, \tau)\right) d \eta\right) \\
& L\left(u_{n+1}(x, t)\right) \\
& =u_{0}(x, 0)+\frac{1}{s}\left\{L\left(\int_{0}^{t} u\left(\eta, u_{n}(\eta, \tau)\right) d \eta\right)\right\}
\end{aligned}
$$

Taking Laplace inverse on both sides of equation (10), we get:

$$
\begin{aligned}
& u_{n+1}(x, t) \\
& =u_{0}(x, 0)+L^{-1}\left[\frac{1}{s}\left\{L\left(\int_{0}^{t} u\left(\eta, u_{n}(\eta, \tau)\right) d \eta\right)\right\}\right]
\end{aligned}
$$

Now, solving equation (11) by usual SAM (such as Taking $n=0,1)$

$$
\begin{aligned}
& u_{2}(x, t) \\
& =u_{0}(x, 0)+L^{-1}\left[\frac{1}{s}\left\{L\left(\int_{0}^{t} u\left(\eta, u_{1}(\eta, \tau)\right) d \eta\right)\right\}\right]
\end{aligned}
$$

Finally, Apply Padé [2,2] Technique of equation (12).

\section{APPLICATION}

In this section, we demonstrate the analysis of numerical methods such as SAM, SAM-Laplace Transformation, and SAM-Laplace-Padé Technique by applying them to the system of nonlinear partial differential Equations (1)

Note that we used MATHEMATICA software to obtain all numerical results using all of the above methods. This is due to its simplicity and powerful manipulation.

The numerical results of System (1) obtained by SAM using three approximate terms can be seen below:

$$
\begin{aligned}
& u(x, t)=u_{2}(x, t) \\
& \begin{aligned}
u(x, t)=\frac{1}{16384} t^{4} & \left(-35640 b^{7} c^{7 / 2}-17820 b^{5} c^{9 / 2}\right. \\
& -2970 b^{3} c^{11 / 2}-165 b c^{13 / 2} \\
& -225504 b^{6} c^{4} \operatorname{Cosh}[\sqrt{c} x] \ldots
\end{aligned}
\end{aligned}
$$

And

$$
\begin{aligned}
v(x, t)=v_{2}(x, t) & \\
v(x, t)=\frac{1}{1024} t^{4}( & 19440 b^{6} c^{7 / 2} \operatorname{Cosh}[\sqrt{c} x] \\
& +9720 b^{4} c^{9 / 2} \operatorname{Cosh}[\sqrt{c} x] \\
& +1620 b^{2} c^{11 / 2} \operatorname{Cosh}[\sqrt{c} x] \ldots
\end{aligned}
$$

Due to the very long resulting series obtained by SAM, this paper only refers to a few parts of the resulting series.

The numerical results of System (1) obtained by SAM-Laplace transformation using three approximate terms can be seen below:

$$
\begin{aligned}
& u(x, t)=u_{2}(x, t) \\
& u(x, t)=\frac{1}{4}\left(-b^{2}+c-2 b \sqrt{c} \operatorname{Sech}[\sqrt{c} x]\right. \\
& \left.-3 c \operatorname{Sech}[\sqrt{c} x]^{2}\right)+\frac{1}{4} t^{2}\left(5 b c^{2} \operatorname{Sech}[\sqrt{c} x]^{3}\right. \\
& +24 c^{5 / 2} \operatorname{Sech}[\sqrt{c} x]^{4} \operatorname{Tanh}[\sqrt{c} x]-\ldots \\
& \text { And } \\
& \begin{aligned}
& v(x, t)=v_{2}(x, t) \\
& v(x, t)=b+\sqrt{c} \operatorname{Sech}[\sqrt{c} x]+ \\
& \frac{1}{2} t^{2}\left(-5 c^{2} \operatorname{Sech}[\sqrt{c} x]^{3} \operatorname{Tanh}[\sqrt{c} x]+\right. \\
&\left.\quad c^{2} \operatorname{Sech}[\sqrt{c} x] \operatorname{Tanh}[\sqrt{c} x]^{3}\right)+\ldots
\end{aligned}
\end{aligned}
$$$$
\left.-3 c \operatorname{Sech}[\sqrt{c} x]^{2}\right)+\frac{1}{4} t^{2}\left(5 b c^{2} \operatorname{Sech}[\sqrt{c} x]^{3} \operatorname{Tanh}[\sqrt{c} x]\right.
$$

Again, due to the very long resulting series obtained by SAMLaplace transformation, this paper only refers to a few parts of the resulting series.

The numerical results of System (1) obtained by SAM-LaplacePadé $[2,2]$ technique using three approximate terms can be seen below:

$$
\begin{aligned}
& u(x, t)=u_{2}(x, t) \\
& u(x, t)=\frac{\frac{1}{4096}\left(-504 b \sqrt{c}-462 b^{2} \operatorname{Cosh}[\sqrt{c} x]-1050 c \operatorname{Cosh}[\sqrt{c} x]-\ldots\right.}{\left(1+\left(\mathrm { t } \left(180 \mathrm{~b} c \operatorname{Sinh}[8 \mathrm{x}]+30 b^{2} \sqrt{c} \operatorname{Sinh}[9 \sqrt{c} x]-\ldots\right.\right.\right.} \\
& \text { And } \\
& \qquad v(x, t)=v_{2}(x, t) \\
& v(x, t)=\frac{\left(\frac{1}{128}(35 b+70 \sqrt{c} \operatorname{Cosh}[\sqrt{c} x]+56 b \operatorname{Cosh}[2 \sqrt{c} x]+\ldots\right.}{1+\frac{t\left(-2322 b^{2} c^{3 / 2} \operatorname{Cosh}[\sqrt{c} x]-387 c^{5} / 2 \cosh [\sqrt{c} x]-\right.}{6 c(43 \operatorname{Sinh}[\sqrt{c} x]+63 \operatorname{Sinh}[3 \sqrt{c} x]+}}
\end{aligned}
$$

Again, due to the very long resulting series obtained by SAMLaplace-Padé technique, this paper only refers to a few parts of the resulting series.

Tables 1 and 2 show the differences between exact and approximate solutions using SAM, SAM-Laplace, and SAMLaplace-Padé $[2,2]$ technique for $u(x, t)$ and $v(x, t)$, respectively, when $x=0.1$ [arbitrary chosen] and $t \in[0,1]$.

Table 1

\begin{tabular}{|c|c|c|c|c|}
\hline $\boldsymbol{u}(\boldsymbol{x}, \boldsymbol{t})$ & Exact & SAM & $\begin{array}{c}\text { SAM- } \\
\text { Laplace }\end{array}$ & $\begin{array}{c}\text { SAM- } \\
\text { Laplace-Padé }\end{array}$ \\
\hline$(\mathbf{0 . 1} \mathbf{0 . 0})$ & -0.00552 & -0.00552 & -0.00552 & -0.00552 \\
\hline$(\mathbf{0 . 1} \mathbf{0 . 2})$ & -0.00552 & -0.00552 & -0.00552 & -0.00552 \\
\hline$(\mathbf{0 . 1} \mathbf{0 . 4})$ & -0.00552 & -0.00552 & -0.00552 & -0.00552 \\
\hline$(\mathbf{0 . 1} \mathbf{0 . 6})$ & -0.00552 & -0.00552 & -0.00552 & -0.00552 \\
\hline$(\mathbf{0 . 1} \mathbf{0 . 8})$ & -0.00552 & -0.00552 & -0.00552 & -0.00552 \\
\hline$(\mathbf{0 . 1} \mathbf{1 . 0})$ & -0.00552 & -0.00552 & -0.00552 & -0.00552 \\
\hline & 4144811 & 3263364 & 365651 & 3659914 \\
\hline
\end{tabular}


Table 2.

\begin{tabular}{|c|c|c|c|c|}
\hline$v(x, t)$ & Exact & SAM & $\begin{array}{c}\text { SAM- } \\
\text { Laplace }\end{array}$ & $\begin{array}{l}\text { SAM- } \\
\text { Laplace- } \\
\text { Padé }\end{array}$ \\
\hline$(0.1,0.0)$ & $\begin{array}{c}0.10999 \\
50002\end{array}$ & $\begin{array}{c}0.10999 \\
50002\end{array}$ & $\begin{array}{c}0.10999 \\
50002\end{array}$ & $\begin{array}{c}0.10999 \\
50002\end{array}$ \\
\hline$(0.1,0.2)$ & $\begin{array}{c}0.10999 \\
48987\end{array}$ & $\begin{array}{c}0.10999 \\
4953\end{array}$ & $\begin{array}{c}0.10999 \\
49176\end{array}$ & $\begin{array}{c}0.10999 \\
49172\end{array}$ \\
\hline$(0.1,0.4)$ & $\begin{array}{c}0.10999 \\
47962\end{array}$ & $\begin{array}{c}0.10999 \\
50233\end{array}$ & $\begin{array}{c}0.10999 \\
47361\end{array}$ & $\begin{array}{c}0.10999 \\
47273\end{array}$ \\
\hline$(0.1,0.6)$ & $\begin{array}{c}0.10999 \\
46926\end{array}$ & $\begin{array}{c}0.10999 \\
52112\end{array}$ & $\begin{array}{c}0.10999 \\
4549\end{array}$ & $\begin{array}{c}0.10999 \\
4495\end{array}$ \\
\hline$(0.1,0.8)$ & $\begin{array}{c}0.10999 \\
45881\end{array}$ & $\begin{array}{c}0.10999 \\
55166\end{array}$ & $\begin{array}{c}0.10999 \\
44403\end{array}$ & $\begin{array}{c}0.10999 \\
4257\end{array}$ \\
\hline$(0.1,1.0)$ & $\begin{array}{c}0.10999 \\
44825\end{array}$ & $\begin{array}{c}0.10999 \\
59395\end{array}$ & $\begin{array}{c}0.10999 \\
44851\end{array}$ & $\begin{array}{c}0.10999 \\
40312\end{array}$ \\
\hline
\end{tabular}

Again, Tables 3 and 4 show the absolute error between the exact solution and approximate solutions by SAM, SAMLaplace, and SAM-Laplace-Padé technique for $u(x, t)$ and $v(x, t)$ respectively, when $x=0.1$ and $t \in[0,1]$.

Table 3.

\begin{tabular}{|c|c|c|c|}
\hline$u(x, t)$ & $\begin{array}{l}\text { |Exact - } \\
\text { SAM | }\end{array}$ & $\begin{array}{l}\text { | Exact-SAM, } \\
\text { Laplace | }\end{array}$ & $\begin{array}{c}\text { | Exact- } \\
\text { SAM,Laplace,Padé | }\end{array}$ \\
\hline$(0.1,0.0)$ & 0 & $\begin{array}{l}2.60209 \\
\times 10^{-18}\end{array}$ & $\begin{array}{r}6.61797 \\
\times 10^{-16}\end{array}$ \\
\hline$(0.1,0.2)$ & $\begin{array}{l}1.07854 \\
\times 10^{-7}\end{array}$ & $\begin{array}{l}8.28985 \\
\times 10^{-9} \\
\end{array}$ & $\begin{array}{c}8.28863 \\
\times 10^{-9} \\
\end{array}$ \\
\hline$(0.1,0.4)$ & $\begin{array}{l}2.49925 \\
\times 10^{-7}\end{array}$ & $\begin{array}{l}6.28147 \\
\times 10^{-8}\end{array}$ & $\begin{array}{c}6.27768 \\
\times 10^{-8}\end{array}$ \\
\hline$(0.1,0.6)$ & $\begin{array}{l}4.26214 \\
\times 10^{-7}\end{array}$ & $\begin{array}{l}1.61643 \\
\times 10^{-7}\end{array}$ & $\begin{array}{c}1.61364 \\
\times 10^{-7}\end{array}$ \\
\hline$(0.1,0.8)$ & $\begin{array}{l}6.36721 \\
\times 10^{-7}\end{array}$ & $\begin{array}{l}3.036 \\
\times 10^{-7}\end{array}$ & $\begin{array}{c}3.02454 \\
\times 10^{-7}\end{array}$ \\
\hline$(0.1,1.0)$ & $\begin{array}{l}8.81447 \\
\times 10^{-7} \\
\end{array}$ & $\begin{array}{l}4.88301 \\
\times 10^{-7} \\
\end{array}$ & $\begin{array}{c}4.84897 \\
\times 10^{-7} \\
\end{array}$ \\
\hline $\begin{array}{l}\text { Least } \\
\text { square } \\
\text { error }\end{array}$ & $\begin{array}{l}2.43015 \\
\times 10^{-13}\end{array}$ & $\begin{array}{l}5.77274 \\
\times 10^{-14}\end{array}$ & $\begin{array}{r}5.7129 \\
\times 10^{-14}\end{array}$ \\
\hline
\end{tabular}

Table 4.

\begin{tabular}{|c|c|c|c|}
\hline $\boldsymbol{v}(\boldsymbol{x}, \boldsymbol{t})$ & $\begin{array}{c}\mid \text { Exact-SAM } \\
\text { | }\end{array}$ & $\begin{array}{c}\mid \text { Exact-SAM, } \\
\text { Laplace } \mid\end{array}$ & $\begin{array}{c}\text { | Exact- } \\
\text { SAM,Laplace,Padé | }\end{array}$ \\
\hline$(\mathbf{0 . 1} \mathbf{0 . 0})$ & 0 & $\begin{array}{l}1.38778 \\
\times 10^{-17}\end{array}$ & $\begin{array}{l}7.34135 \\
\times 10^{-15}\end{array}$ \\
\hline$(\mathbf{0 . 1} \mathbf{0 . 2})$ & $\begin{array}{l}1.07854 \\
\times 10^{-7}\end{array}$ & $\begin{array}{l}1.88647 \\
\times 10^{-8}\end{array}$ & $\begin{array}{c}1.85192 \\
\times 10^{-8}\end{array}$ \\
\hline$(\mathbf{0 . 1} \mathbf{0 . 4})$ & $\begin{array}{l}2.49925 \\
\times 10^{-7}\end{array}$ & $\begin{array}{l}6.00576 \\
\times 10^{-8}\end{array}$ & $\begin{array}{l}6.8925 \\
\times 10^{-8}\end{array}$ \\
\hline$(\mathbf{0 . 1} \mathbf{0 . 6})$ & $\begin{array}{l}4.26214 \\
\times 10^{-7}\end{array}$ & $\begin{array}{l}1.43673 \\
\times 10^{-7}\end{array}$ & $\begin{array}{c}1.97651 \\
\times 10^{-7}\end{array}$ \\
\hline$(\mathbf{0 . 1} \mathbf{0 . 8})$ & $\begin{array}{l}6.36721 \\
\times 10^{-7}\end{array}$ & $\begin{array}{l}1.47818 \\
\times 10^{-7}\end{array}$ & $\begin{array}{c}3.31063 \\
\times 10^{-7}\end{array}$ \\
\hline$(\mathbf{0 . 1} \mathbf{1 . 0})$ & $\begin{array}{l}8.81447 \\
\times 10^{-7}\end{array}$ & $\begin{array}{l}2.58779 \\
\times 10^{-9}\end{array}$ & $\begin{array}{c}4.51328 \\
\times 10^{-7}\end{array}$ \\
\hline $\begin{array}{c}\text { Least } \\
\text { square } \\
\text { error }\end{array}$ & $\mathbf{5 . 3 4 2 3}$ & $\mathbf{9 . 3 8 9 3 5}$ & $\mathbf{6 . 0 0 8 1 9}$ \\
$\times \mathbf{1 0}^{-13}$ & $\times \mathbf{1 0}^{-15}$ & $\times \mathbf{1 0}^{-14}$ \\
\hline
\end{tabular}

Also, the Fig. 2, Fig. 3, Fig. 4, and Fig. 5 below are the surfaces for the exact solution of J.M system, SAM, SAMLaplace, and SAM-Laplace-Padé $[2,2]$ technique, respectively, when $x \in[-20,20]$ and $t \in[0,1]$.

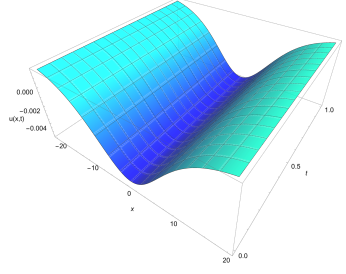

(a) $u(x, t)$

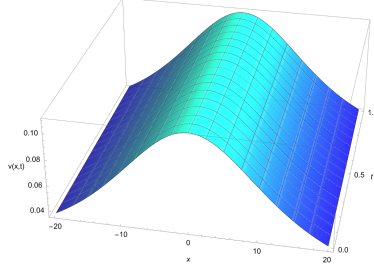

(b) $v(x, t)$
Fig. 2 The surfaces of exact solutions.

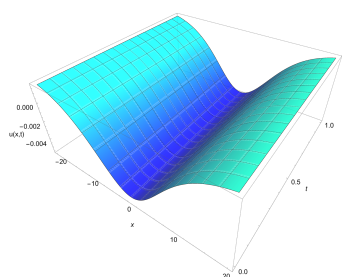

(a) $\boldsymbol{u}(\boldsymbol{x}, \boldsymbol{t})$

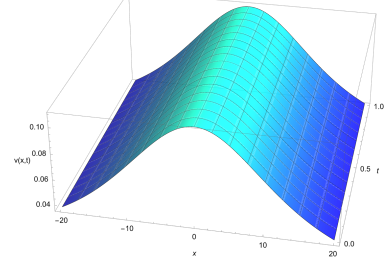

(b) $v(x, t)$
Fig. 3 The surfaces of SAM solutions.

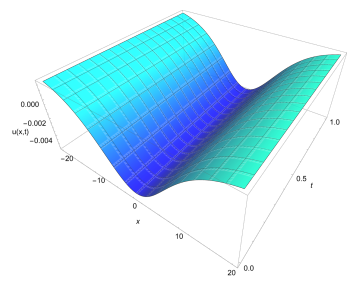

(a) $u(x, t)$

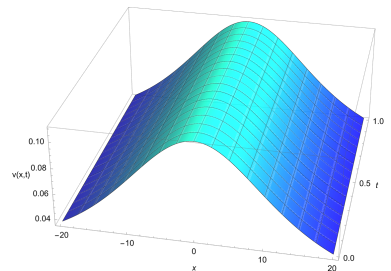

(b) $v(x, t)$
Fig. 4 The surfaces of SAM-Laplace solutions.

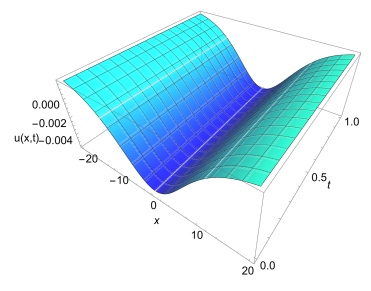

(a) $u(x, t)$

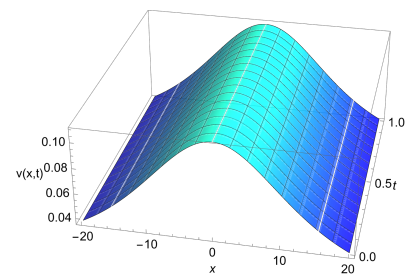

(b) $v(x, t)$
Fig. 5 The surfaces of SAM-Laplace-Padé solutions.

The Curves in Fig. 6, Fig. 7, Fig. 8, Fig. 9, Fig. 10, and Fig. 11 show us how the SAM, SAM-Laplace, and SAM-LaplacePadé $[2,2]$ curves are close to the exact solution curve, when $x=\mathbf{0 . 1}$ and $t$ has different values $t=\{10,30,50,100\}$. The reason for that is to show how the method are stable when we increase the value of $t$, but as $t$ increases, we see the SAMLaplace curve blows up and diverges from the exact solution curve while SAM and SAM-Laplace-Padé curve preserves its path with the exact solution curve. Although the curves cannot give us the precise results as can be seen from Tables 3 and 4, the reason for this will be explained later.

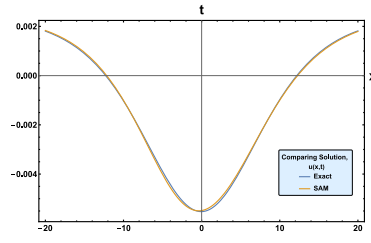

(a) $x \in[-20,20]$ and $t \in[0,10]$

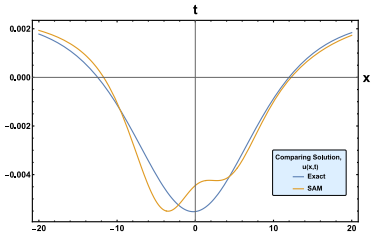

(b) $x \in[-20,20]$ and $t \in[0,50]$ 


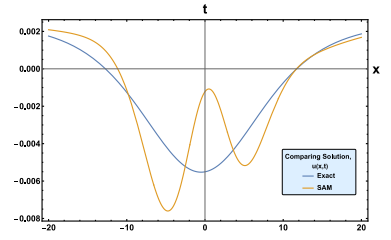

(c) $x \in[-20,20]$ and $t \in[0,100]$

Fig. 6 The Curves of SAM for different values of $t$ for $u(x, t)$

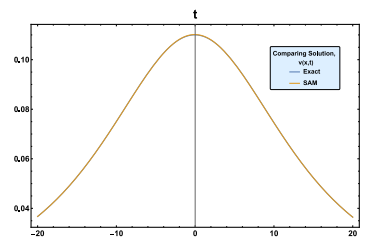

(a) $x \in[-20,20]$ and $t \in[0,10]$

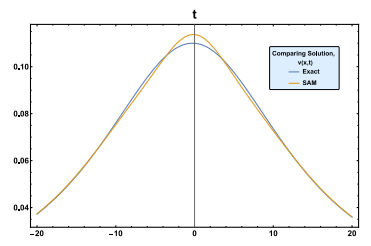

(b) $x \in[-20,20]$ and $t \in[0,50]$

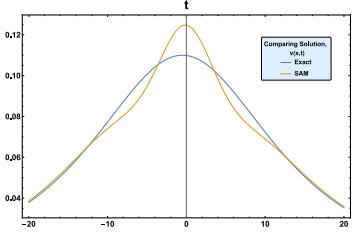

(c) $x \in[-20,20]$ and $t \in[0,100]$

Fig. 7 The Curves of SAM for different values of $t$ for $v(x, t)$

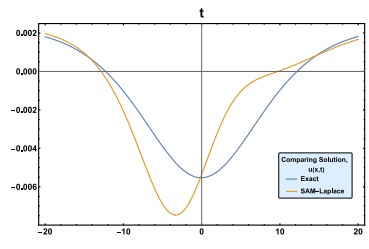

(a) $x \in[-20,20]$ and $t \in[0,10]$

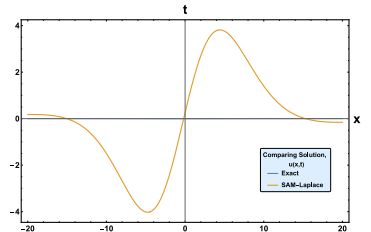

(b) $x \in[-20,20]$ and $t \in[0,50]$

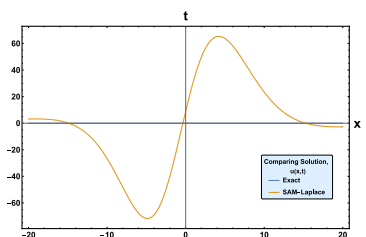

(c) $x \in[-20,20]$ and $t \in[0,100]$

Fig. 8 The Curves of SAM-Laplace for different values of $t$ for $u(x, t)$ (a) $x \in[-20,20]$ and $t \in[0,10]$

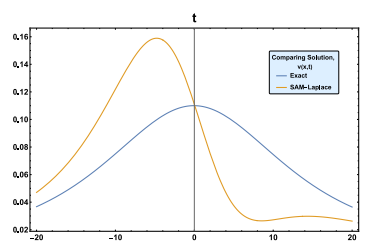

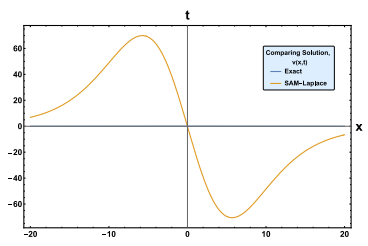

(b) $x \in[-20,20]$ and $t \in[0,50]$

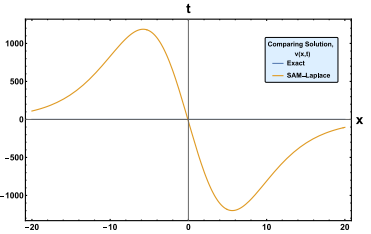

(c) $x \in[-20,20]$ and $t \in[0,100]$

Fig. 9 The Curves of SAM-Laplace for different values of $t$ for $v(x, t)$

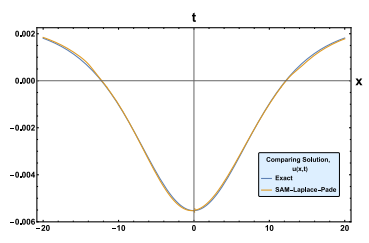

(a) $x \in[-20,20]$ and $t \in[0,10]$

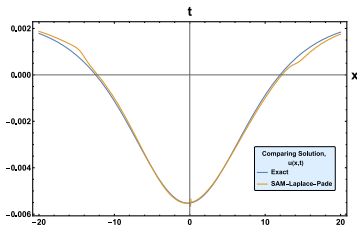

(b) $x \in[-20,20]$ and $t \in[0,50]$

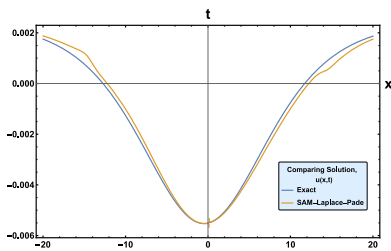

(c) $x \in[-20,20]$ and $t \in[0,100]$

Fig. 10 The Curves of SAM-Laplace-Padé for different values of $t$ for $u(x, t)$

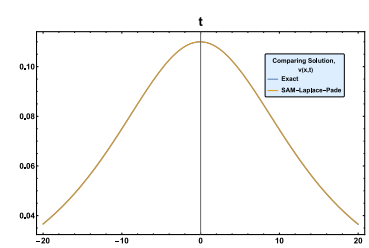

(a) $x \in[-20,20]$ and $t \in[0,10]$

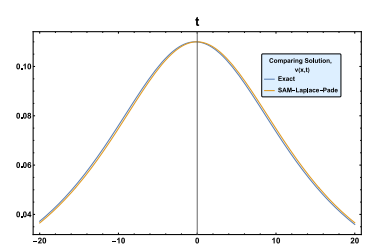

(b) $x \in[-20,20]$ and $t \in[0,50]$

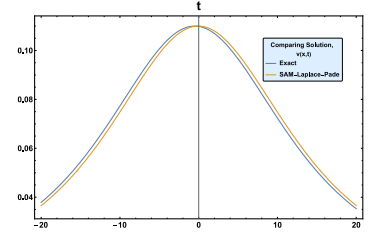

(c) $x \in[-20,20]$ and $t \in[0,100$

Fig. 11 The Curves of SAM-Laplace-Padé for different values of $t$ for $v(x, t)$

Again, the family curves in Fig. 12 and Fig. 13 show how the SAM and the SAM-Laplace-Padé $[2,2]$ curves are close to the exact solution curve when $x=\mathbf{0 . 1}$ and $t$ has different values $t=$ $\{10,30\}$, which indicate that the curves preserve their path with the exact solution curve. As its evident from the results, the SAM-Laplace method does not preserve its path with the exact solution curve. Thus, to overcome this flaw, we combine Padé $[2,2]$ technique into it for solving the system of (JM) equations.

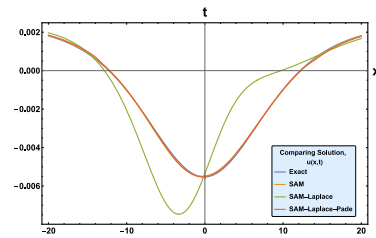

(a) $x \in[-20,20]$ and $t \in[0,10]$

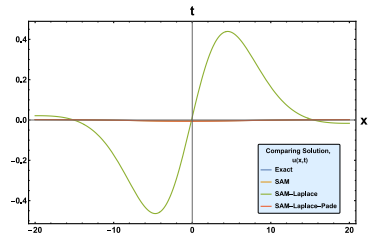

(b) $x \in[-20,20]$ and $t \in[0,30]$
Fig. 12 The Family Curves of SAM, SAM-Laplace, SAM-Laplace-Padé for different values of $t$ for $u(x, t)$

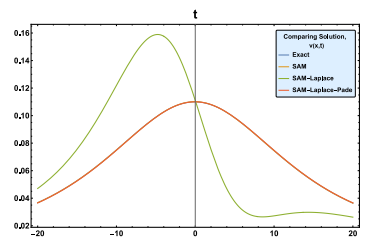

(a) $x \in[-20,20]$ and $t \in[0,10]$

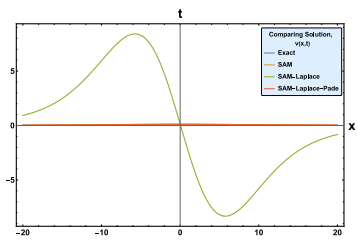

(b) $x \in[-20,20]$ and $t \in[0,30]$
Fig. 13 The Family Curves of SAM, SAM-Laplace, SAM-Laplace-Padé for different values of $t$ for $v(x, t)$

Finally, to see the precise difference exactly when $t$ increases, Tables 5 and 6 show the least square errors between SAM, SAMLaplace, and SAM-Laplace-Padé $[2,2]$ when $x=0.1$ and $t \in$ $[0,100]$. 
Table 5.

\begin{tabular}{|c|c|c|c|}
\hline$u(\boldsymbol{x}, \boldsymbol{t})$ & $\begin{array}{c}\text { | Exact- } \\
\text { SAM }\end{array}$ & $\begin{array}{c}\text { | Exact-SAM, } \\
\text { Laplace | }\end{array}$ & $\begin{array}{c}\text { | Exact- } \\
\text { SAM,Laplace,Padé | }\end{array}$ \\
\hline $\begin{array}{c}\text { Least square } \\
\text { error }\end{array}$ & $\begin{array}{c}\mathbf{3 . 7 7 2 9} \\
\times \mathbf{1 0}^{-4}\end{array}$ & $\begin{array}{l}\mathbf{1 . 2 1 5 1 8} \\
\times \mathbf{1 0}^{3}\end{array}$ & $\begin{array}{c}\mathbf{2 . 9 1 5 0 5} \\
\times \mathbf{1 0}^{-5}\end{array}$ \\
\hline
\end{tabular}

Table 6.

\begin{tabular}{|c|c|c|c|}
\hline$v(x, t)$ & $\begin{array}{c}\text { | Exact- } \\
\text { SAM | }\end{array}$ & $\begin{array}{c}\text { | Exact-SAM, } \\
\text { Laplace | }\end{array}$ & $\begin{array}{c}\text { | Exact - } \\
\text { SAM,Laplace,Padé | }\end{array}$ \\
\hline $\begin{array}{c}\text { Least square } \\
\text { error }\end{array}$ & $\begin{array}{l}\mathbf{4 . 3 9 6 9 7} \\
\times \mathbf{1 0}^{-3}\end{array}$ & $\begin{array}{l}3.52589 \\
\times \mathbf{1 0}^{\mathbf{4}}\end{array}$ & $\begin{array}{c}\mathbf{6 . 8 5 4 4 8} \\
\times 10^{-7}\end{array}$ \\
\hline
\end{tabular}

\section{CONCLUSION}

In this paper, a strongly nonlinear system of partial differential equations, which is well known as (JM) equation, was solved numerically by using Successive approximation method, Successive approximation with Laplace, and Successive approximation with Laplace then Padé [2, 2] technique. From the results obtained by Tables 1-4 and Figures 6(a), 7(a), 10(a), and 11(a), we can conclude that SAM-Laplace and SAM-Laplace-Padé [2,2] methods perform better than SAM when $t$ is small in terms of least square error. Moreover, the results obtained from Tables 5-6 and Figures 6-13 indicate that with increasing $t$, SAMLaplace deviates from the exact solution, while SAM and SAM-Laplace-Padé $[\mathbf{2 , 2}]$ keep their trajectory with the exact solution. However, SAM-Laplace-Padé [2,2] gives better results than SAM in terms of least squared error despite the t-value used as shown in Table 5-6. In general, the results validated the efficiency and the accuracy of the proposed two techniques: SAM-Laplace and SAMLaplace-Padé $[\mathbf{2 , 2}]$ in terms of least square error. This due to the fact of combining Laplace and Laplace-Padé [2,2] methods into SAM. One point to mention here is that this conclusion is limited to solving this kind of strong nonlinear system of partial differential equations. Thus, for future work, we aim to apply these modification techniques to all types of equations.

\section{REFERENCES}

Abassy, T. A., El-Tawil, M. A. \& El-Zoheiry, H. (2007). Exact solutions of some nonlinear partial differential equations using the variational iteration method linked with Laplace transforms and the Padé technique.
Computers \& Mathematics with Applications, 54(7), 940954.

https://doi.org/https://doi.org/10.1016/j.camwa.2006.12.0 67

Adam, B. A. A. (2015). A comparative study of successive approximations method and He-Laplace method. Journal of Advances in Mathematics and Computer Science, 129145.

Fan, E. (2003). Uniformly constructing a series of explicit exact solutions to nonlinear equations in mathematical physics. Chaos, Solitons \& Fractals, 16(5), 819-839.

Hashem, H. H. G. (2015). On successive approximation method for coupled systems of Chandrasekhar quadratic integral equations. Journal of the Egyptian Mathematical Society, 23(1), 108-112.

Jafari, H. (2014). A comparison between the variational iteration method and the successive approximations method. Applied Mathematics Letters, 32, 1-5.

Jalili, M., Baktash, E. \& Ganji, D. D. (2008). Application of He's homotopy-perturbation method to strongly nonlinear coupled systems. Journal of Physics: Conference Series, 96(1), 12078.

Mahavidyalaya, U. (2012). Laplace substitution method for solving partial differential equations involving mixed partial derivatives. International Journal of Pure and Applied Mathematics, 78(7), 973-979.

Manaa, S. A., Easif, F. H. \& Mahmood, B. A. (2013). Successive Approximation Method for Solving Nonlinear Diffusion Equation with Convection Term. IOSR Journal of Engineering, 3, 28-31.

Mohamed, M. A. \& Torky, M. S. (2013). Numerical solution of nonlinear system of partial differential equations by the Laplace decomposition method and the Pade approximation. American Journal of Computational Mathematics, 3(3), 175.

Sabali, A. J., Manaa, S. A. \& Easif, F. H. (2018). Adomian and Adomian-Padé Technique for Solving Variable Coefficient Variant Boussinesq System. Science Journal of University of Zakho, 6(3), 108-111.

Tracinà, R. \& Khalique, C. M. (n.d.). Recent Advances in Symmetry Groups and Conservation Laws for Partial Differential Equations and Applications.

Veeresha, P., Prakasha, D. G., Magesh, N., Nandeppanavar, M. M. \& Christopher, A. J. (2019). Numerical simulation for fractional Jaulent-Miodek equation associated with energy-dependent Schrödinger potential using two novel techniques. Waves in Random and Complex Media, 1-22. 